|| ISSN(online): 2589-8698 || ISSN(print): 2589-868X ||

International Journal of Medical and Biomedical Studies Available Online at www.ijmbs.info

NLM (National Library of Medicine ID: 101738825)

Index Copernicus Value 2020: 79.44

\title{
MANAGEMENT OF MULTIPLE MAXILLOFACIAL FRACTURE WITH MILD HEAD INJURY
}

\section{Putri Nurfuadah $^{1 *}$, Endang Sjamsudin ${ }^{2}$, Abel Tasman Yuza ${ }^{3}$, Seto Adiantoro ${ }^{4}$, M.Z. Arifin ${ }^{5}$}

${ }^{1}$ Resident of Oral and Maxillofacial Surgery Department. Faculty of Dentistry, Universitas Padjadjaran/ RSUP Dr. Hasan Sadikin Bandung, Indonesia

${ }^{2,3,4}$ Staff of Oral and Maxillofacial Surgery Department. Faculty of Dentistry, Universitas Padjadjaran/ RSUP Dr. Hasan Sadikin Bandung, Indonesia

${ }^{5}$ Staff of Neurosurgery Department, RSUP Dr. Hasan Sadikin, Faculty of Medicine, Universitas Padjadjaran, Bandung, Indonesia

Article Info: Received 13 December 2021; Accepted 16 January 2022

DOI: https://doi.org/10.32553/ijmbs.v6i1.2388

Corresponding author: Putri Nurfuadah

Conflict of interest: No conflict of interest.

\section{Abstract}

Introduction: Maxillofacial fracture is an injury that is often followed by head injury. Maxillofacial fractures vary in their severity, some involves either a single bone or several complex bones, depending on the force degree of impact on the face region. A comprehensive management can prevent more severe complications of head injury. This case report describes the management of multiple maxillofacial fractures with head injury.

Case report: A 26-year-old female patient came to the Emergency Department of RSUP Dr. Hasan Sadikin Bandung with complaints of fractures in the facial bones and headaches due to an accident. Physical examination revealed facial asymmetry, edema, and hematomas in the bilateral periorbita, right and left mandible, and mental region. The patient had performed a CT scan of the head before and it appeared that there was a soft tissue swelling in the left temporal region, as well as bone discontinuities in the left zygoma and left mandibular angle with sulcus and gyrus, sylvian fissure, uncompressed ventricles and cisterns and no midline shift. The patient underwent definitive treatment with open reduction intermaxillary fixation (ORIF) for multiple maxillofacial fractures and conservative treatment for her head injury.

Conclusion: The success of maxillofacial fracture treatment with head injury is strongly determined by accuracy in the initial assessment and comprehensive treatment involving multidisciplinary. Head injuries need priority treatment followed by treatment of maxillofacial fractures.

Keywords: Multiple maxillofacial fractures, Head injury, Open reduction (ORIF), Close reduction

\section{Introduction}

Topographically, the face is an unprotected part of the body and is easily exposed to trauma, so that facial injuries are the most common type of injury. Facial (maxillofacial) fractures are more often caused by motor vehicle accidents, sports trauma, falls and violence or fights, so that those are generally multi-traumatic cases. Although maxillofacial fractures rarely require immediate surgical intervention, accompanying structural brain injuries are often a surgical emergency. ${ }^{1,2,3,4,5}$

Facial trauma often causes injury to soft tissues, teeth, bone components including mandible, maxilla, zygoma, ethmoid naso-orbital complex and supraorbital. Facial fractures vary in their severity, some involves one bone or several complex bones, depending on the force degree on the facial. Facial fractures can result in deformity and loss of facial function that affects the social life of the patient. To make a diagnosis, a facial fracture requires proper history taking, clinical and radiographic examination. Radiographic examination is very essential in studying and evaluating a fracture. ${ }^{2,5,6}$

Anatomically, the head is divided into the skull (cranium) and the facial bones. The skull bones consist of the calvary bones and the skull base bones, while the facial bones consist of the maxilla, zygoma, lacrimal, nasal, and vomer bone. These bones are interconnected and support each other to form the skeleton of the head, so that when a fracture occurs in the midfacial area, several bones that form the cranial base, such as the sphenoid, frontal and ethmoid, are often involved. 1,2,4

Maxillofacial fractures cannot be separated from head injuries because of their adjacent location and structures. Patients of maxillofacial fractures are often accompanied by head injuries, such as intracranial hemorrhage, skull 
base fractures and decreased consciousness which can result in damage to the central nervous system. In Indonesia, the incidence of head injuries annually is estimated at 500,000 cases. Of these numbers, $10 \%$ of patients died before arriving at the hospital. Among the patients who arrived at the hospital, $80 \%$ were classified as mild head injuries, $10 \%$ were categorized to moderate injuries, and $10 \%$ were included as severe head injuries. $3,5,6$

Head injury is a series of pathophysiological events that occur after head trauma which can involve the scalp, bone and brain tissue or a combination thereof. Head injuries were classified according to the Glasgow Coma Scale (GCS) score. A GCS score equal to or less than 8 was defined as a severe head injury, GCS score of 9-13 as a moderate head injury, and a GCS score of 14-15 as a mild head injury. Management of head injury patients is carried out in an integrated manner including primary survey and secondary survey. $4,5,7,8,10$

Head injury due to trauma is the leading cause of death and disability. Apart from bone, the brain is also protected by a fibrous layer, known as the meninges and a fluid that can functionate as shock absorption. When injury occur, the brain can lose function even without visible damage to the head. Pressure that occurs on the head can be in the form of injury or direct shock to the brain, because of reflection against the inner walls of the cranial cavity. Trauma can cause bleeding in the cavity around the brain, bruising of the brain tissue or damage to nerve connections within the brain; or in other words, patients with head injuries can involve every component from the outer soft tissue layers, skull fractures and injuries to the brain. ${ }^{10,11,12,13}$

Examination of patients with maxillofacial fractures consists of 3 stages, initial examination and treatment of life-threatening conditions, general clinical examination of the patient, and local examination of the maxillofacial and cervical regions. Patients with maxillofacial fractures might experienced other injuries of their body, which could be the true-life threat and a higher priority than the maxillofacial trauma. Therefore, it is always necessary to quickly examine the injured patient and perform emergency resuscitation before proceeding with a more detailed examination. ${ }^{5,8,14}$

Emergency management of patients with maxillofacial trauma with head injury should receive immediate attention to the respiratory tract, adequacy of ventilation, control of internal and external bleeding. The initial assessment (primary survey) in this trauma patient case was based on Advance Trauma Life Support (ATLS), from the American College of Surgeons (ACS). The primary survey was an assessment of Airway clear with C-Spine control, Breathing-ventilation-oxygenation, Circulation, Disabilityneurologic status, and Exposure-environment, body temperature $(\mathrm{ABCDE})$. The $\mathrm{ABCDE}$ assessment is a priority examination based on the type of wound, vital signs and mechanism of injury, so that life-threatening conditions are quickly recognized, and resuscitation is carried out immediately. ${ }^{14,15,16}$

The goal of head injuries and maxillofacial management is to restore the function by ensuring the unification of the bone segments in events of a fracture and restoring the strength as it was before injury, preventing contour defects that may arise and preventing infections. Head injury is a serious condition, so that immediate help is needed. The prognosis of head injury patients will be better if the management is carried out appropriately and quickly. Comprehensive management can prevent more severe complications of head injury. The aim of this case report is to present an initial assessment and comprehensive treatment that involves multidisciplinary. Head injuries need priority treatment followed by treatment of maxillofacial fractures. ${ }^{6,8,17}$

\section{CASE REPORT}

A 26-year-old female patient presented with headaches and facial fractures. Two days earlier, she had a motorcycle accident at high speed and fell down with the mechanism of her face hit the asphalt first. History of using a helmet $(+)$ half-face, history of unconsciousness (-), nausea and vomiting (-), bleeding from mouth (+), bleeding from nose $(-)$, and bleeding from ear (-). The patient was previously taken to a private hospital for a blood lab examination, chest X-ray, head CT scan, and hospitalized for 2 days, then referred to the Emergency Installation of Hasan Sadikin Hospital. The patient had a history of diabetes mellitus and was previously treated with insulin during her hospital stay.

In the primary survey, it was found A: clear with C-spine control, B: symmetrical chest shape and movement, right Vesicular Breath Sound equal to the left, respiration 22 times per minute, C: pulse 84 times per minute, D: GCS assessment 15 (E4M6V5), the pupil is round isochore with a diameter of $3 \mathrm{~mm}$, the left eye is the same as the right one, there is no disturbance of light reflex, and there is no paresis. The secondary survey showed edema on the left clavicle.

In the general examination of the patient, it was found a positive skin turgor, facial head asymmetry, edema, and hematomas in the bilateral periorbita, right and left mandible, and mental regions. Non-anemic on conjunctival examination, and non-icteric sclera. Examination of the neck showed that the jugular venous pressure (JVP) was not elevated, and the submandibular lymph nodes were not palpable and painless. Thoracic examination revealed a discontinuity in the left clavicle. Examination of the lungs, heart, abdomen, and liver were within normal limits. Extremities was felt warm and capillary refill time was less than 2 seconds.

The extraoral local status showed edema and hematoma on the bilateral periorbita, right and left mandibles and the chin 
(Fig. 1). Intra-oral examination showed that tooth 21 had avulsion and laceration on the surrounding gingiva sized $1 \times 0.5 \times 0.5 \mathrm{~cm}$, irregular edges, and based on bone. On the palate, there was a laceration with a size of $4 \times 0.5 \times 0.5 \mathrm{~cm}$, irregular edges, and based on bone. Examination of the buccal mucosa, tongue, floor of the mouth, and tonsils was within normal limits (Fig. 2).

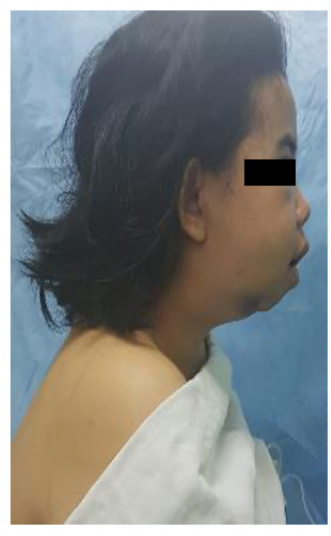

A

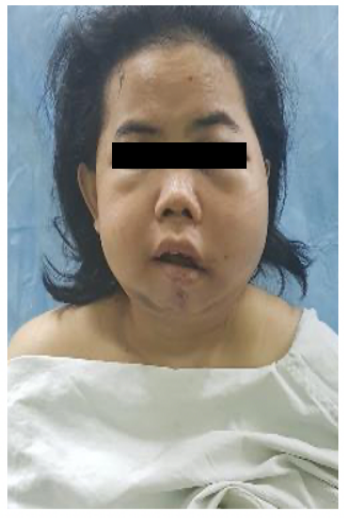

B

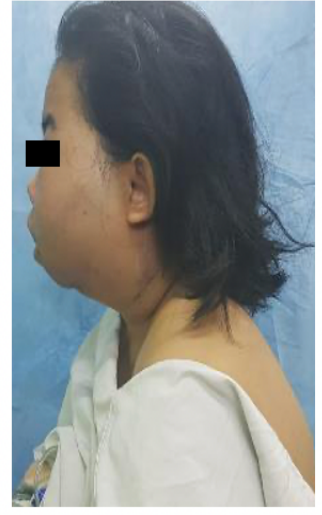

C

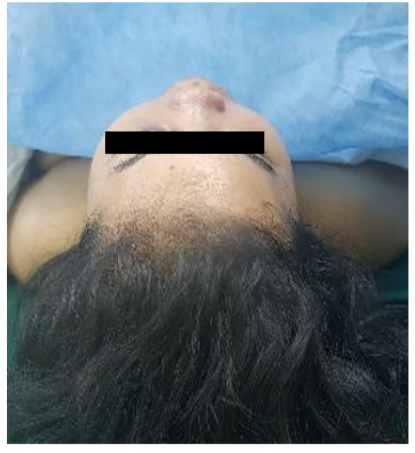

D

Figure 1. Clinical picture of extra oral face (A) right lateral (B) anterior aspect (C) left lateral (D)superior aspect

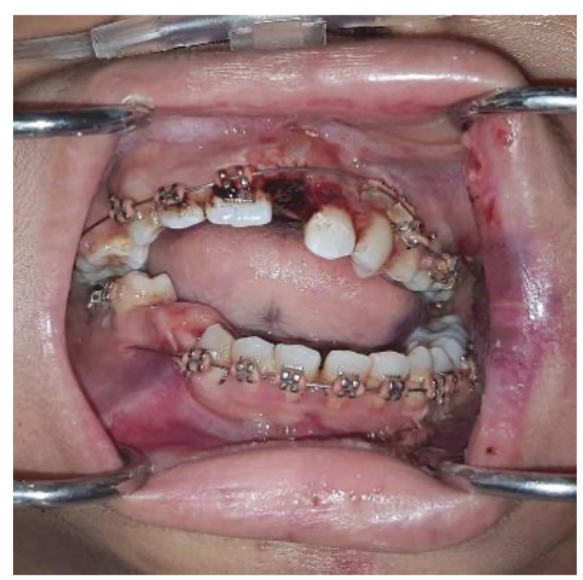

A

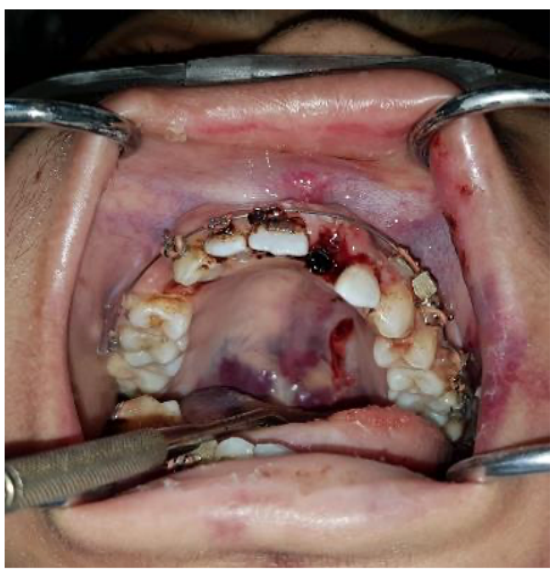

B

Figure 2. Intra oral picture (A) Laceration seen at vestibulum and maxillary gingiva (B) Laceration seen at maxillary gingiva and palate

Hematological examination showed the level of Hemoglobin of $10.9 \mathrm{~g} / \mathrm{dL}$ below normal (12.3-15.3 g/dL), hematocrit 31.3\% below normal (40-52\%), leukocyte count $15.20 \mathrm{~mm} 3$ above normal (4.40-11.30 mm3), erythrocytes $4.05 \mathrm{million} / \mathrm{uL}$ below normal (4.50-5.30 million/uL), SGOT $73 \mathrm{u} / \mathrm{L}$ above normal ( $<37 \mathrm{u} / \mathrm{L})$, SGPT $158 \mathrm{u} / \mathrm{L}$ above normal $(<41 \mathrm{u} / \mathrm{L})$, GDS $342 \mathrm{mg} / \mathrm{dL}$ above normal (70-115 mg/dL), Urea $61 \mathrm{mg} / \mathrm{dL}$ above normal (15-39 mg/dL), Creatinine 0.6 mg/dL below normal (0.7-1.3 $\mathrm{mg} / \mathrm{dL}$ ). Covid-19 screening was carried out by rapid-test with non-reactive results. A chest X-ray revealed a fracture of the left clavicle (Fig. 3). 


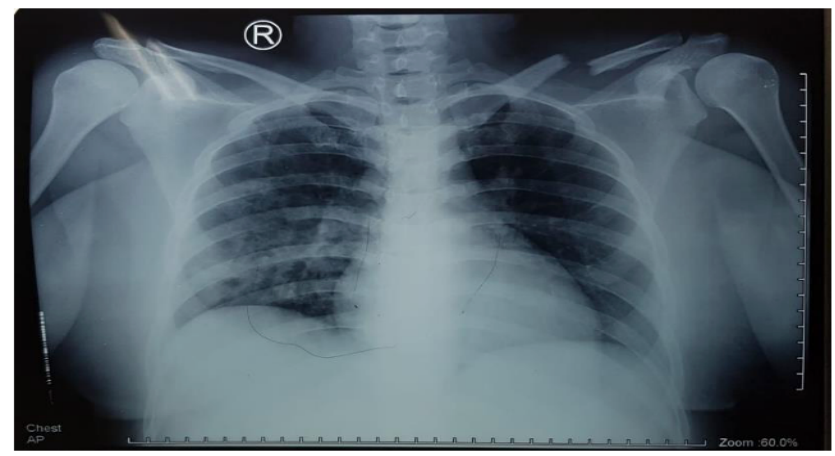

Figure 3. Thorax photo, fracture of the left clavicle is seen

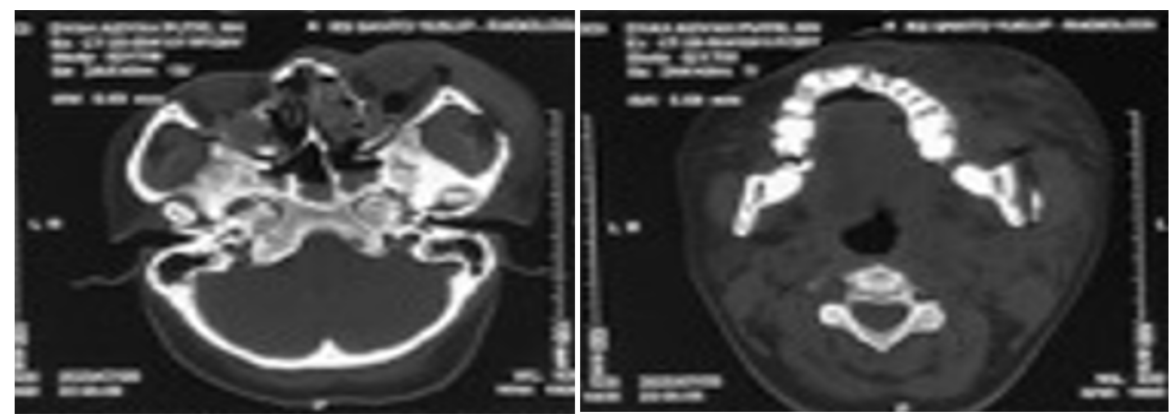

Figure 4. CT Scan of Head

CT scan of the head showed soft tissue swelling in the left temporal. There are bony discontinuities in the left zygoma, left mandibular angle, uncompressed sulcus and gyrus, uncompressed sylvian fissure, uncompressed ventricle, uncompressed cisterna, and no midline shift (Fig. 4).
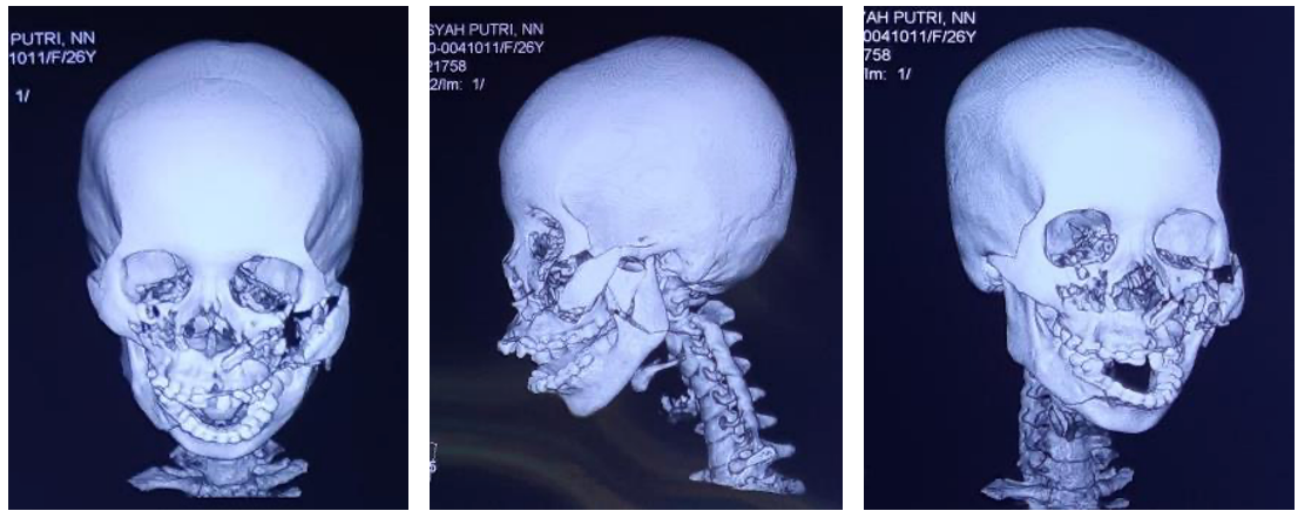

Figure 5. CT Scan 3D

From the 3D facial CT scan, there is discontinuity at lateral and inferior aspect of the left orbital rim bone, discontinuity at inferior aspect of the right orbital rim bone, bone discontinuities in the four supporting walls of the left zygoma bone: left zygomaticomaxillary, frontozygomatic, zygomaticosphenoid, and zygomaticotemporal, discontinuity of left angle of mandible bone, and discontinuity of left para-symphysis mandible bone (Fig. 5).
The diagnose in this case was mild head injury, bilateral inferior aspect of orbital rim fracture + nasal fracture + left tetrapod zygoma fracture + Le Fort I fracture + type III palate fracture + right mandibular para-symphysis fracture + left mandibular angle fracture + left mandibular ramus fracture + fracture at left clavicle transverse displaced + reactive hyperglycemia dd/DM type I + Transaminitis et causa trauma. 
Prior to the treatment, informed consent was made regarding all procedures and treatments to be taken. Emergency measures performed by the neurosurgery department were observing the patient's consciousness with GCS assessment, and vital signs, head position of the patient 30 degrees, oxygenation with a nasal cannula 2-4 liters per minute, infusion of $0.9 \% \mathrm{NaCl} 1500 \mathrm{cc}$ per day, and non-operative conservative treatment. Whereas emergency measures from the Oral and Maxillofacial Surgery Department were the injection of tetagam, the antibiotic Ceftriaxone 1 gram, the analgesic Ketorolac 30 milligrams, then the patient was admitted to the inpatient room.
After the 7th day, Open Reduction Internal Fixation was performed out. The operation procedure began with the installation of the Erich arch bar (interdental wiring) on the upper jaw (tooth 17-27) and the lower jaw (tooth 37-47). The incision was made through an extra-oral approach at the left angle and intra-oral in the right and left maxilla and right para-symphysis to identify fracture fragments and install plate screws. IMF elastic rubber on the Erich arch bar helps reduce fracture fragments with guided occlusion. Plates and screws were installed with 12 holes 10 screws in the right para-symphysis region and left angle, as well as 6 holes bridge 4 screws in the right maxillary region and a maxillary plate 14 holes 12 screws in the left maxillary region (Fig. 6).
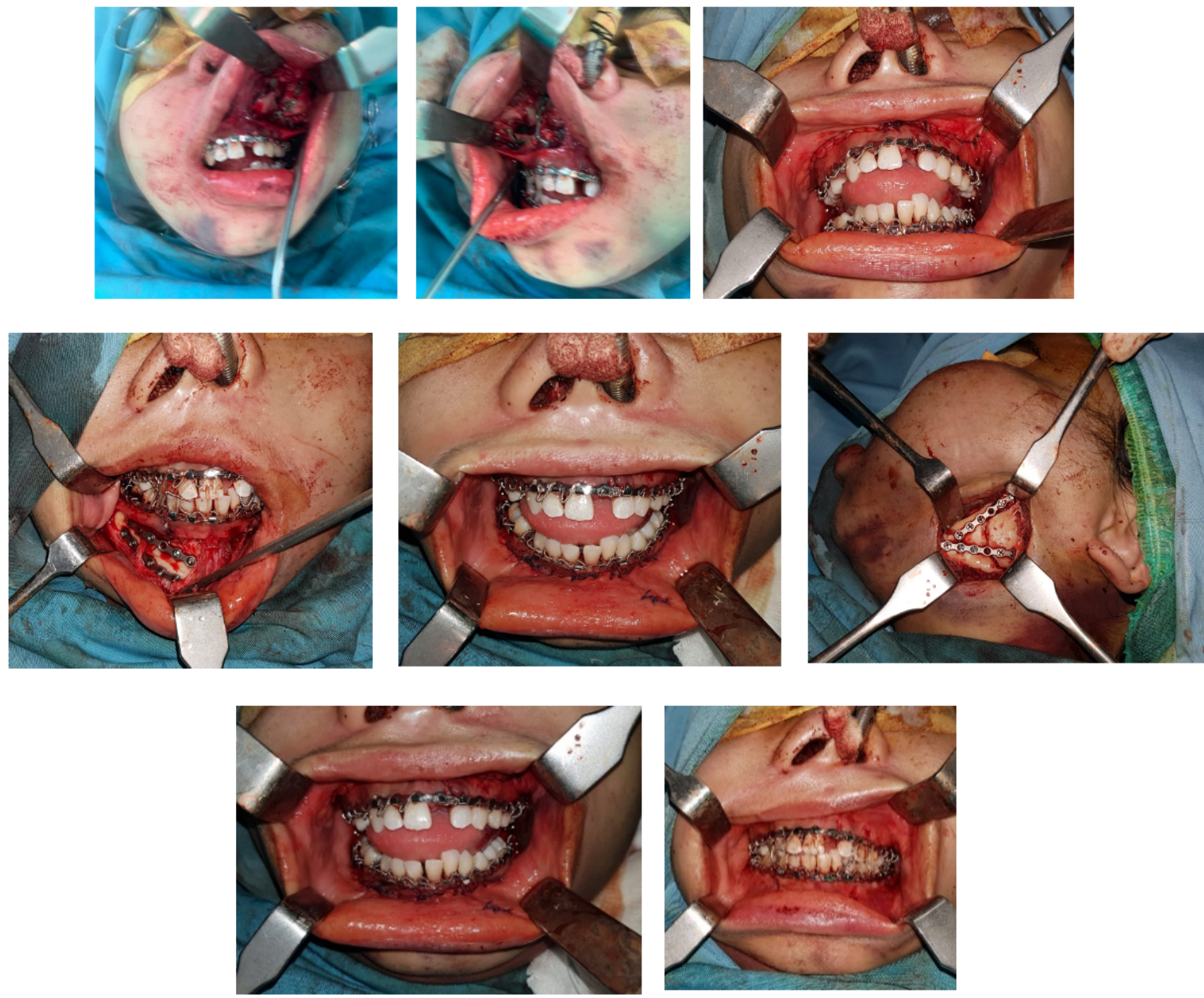

Figure 6. Intra Op

On the first postoperative day, intermaxillary fixation (IMF) was performed using an elastic rubber (interarch elastic). From the second day, intermaxillary fixation (IMF) was performed using a wire (Fig. 7). 


\begin{tabular}{|l|l|}
\hline Putri Nurfuadah et al. & International Journal of Medical and Biomedical Studies (IJMBS) \\
\hline
\end{tabular}
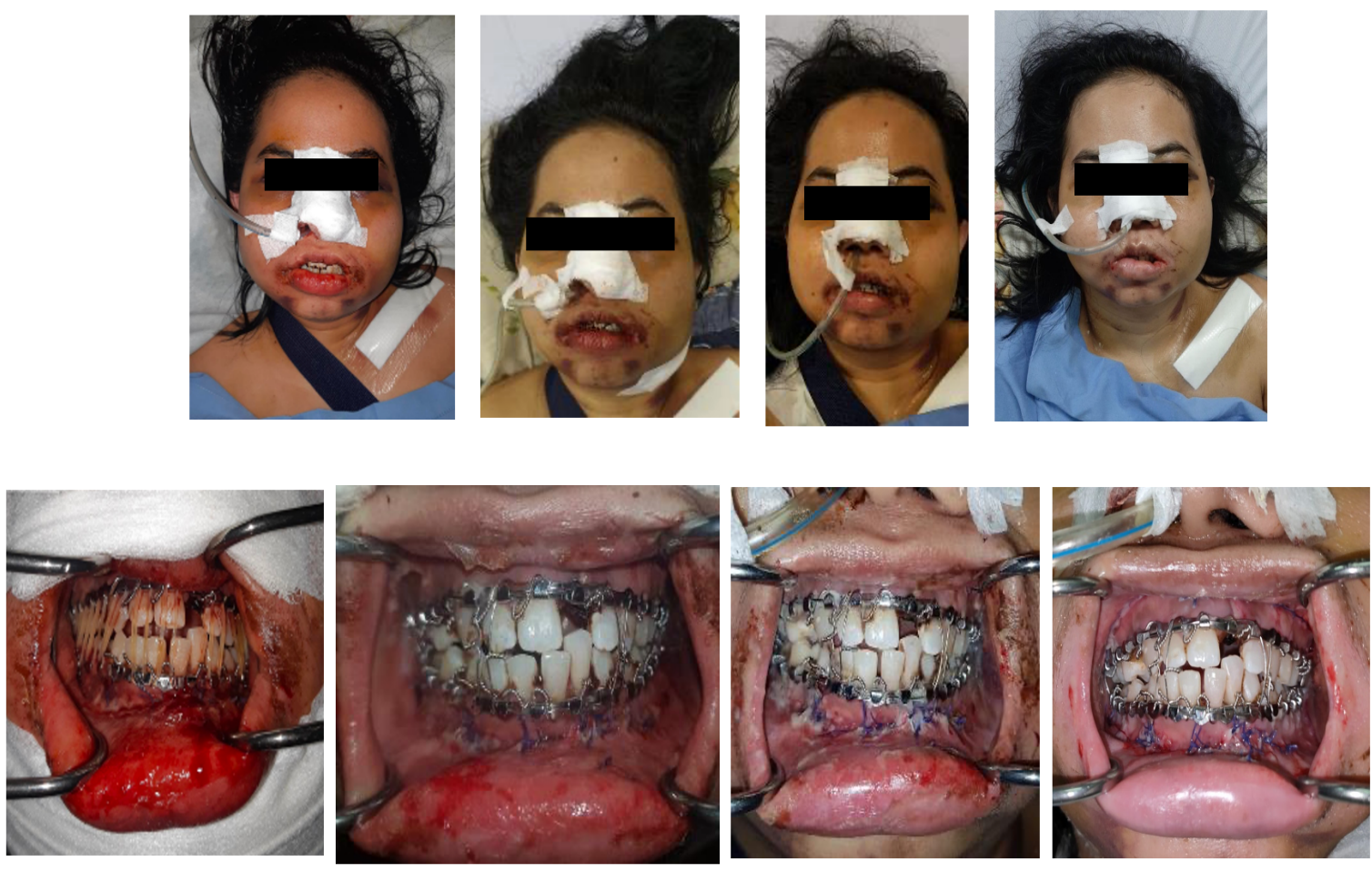

Figure 7. Post Operative Day 1-4

The patient was observed in the inpatient room for 8 days. Oral hygiene was monitored and the edema in the eye region and cheek area was decreasing day by day. The patient was educated for a temporary liquid diet (Fig. 8).
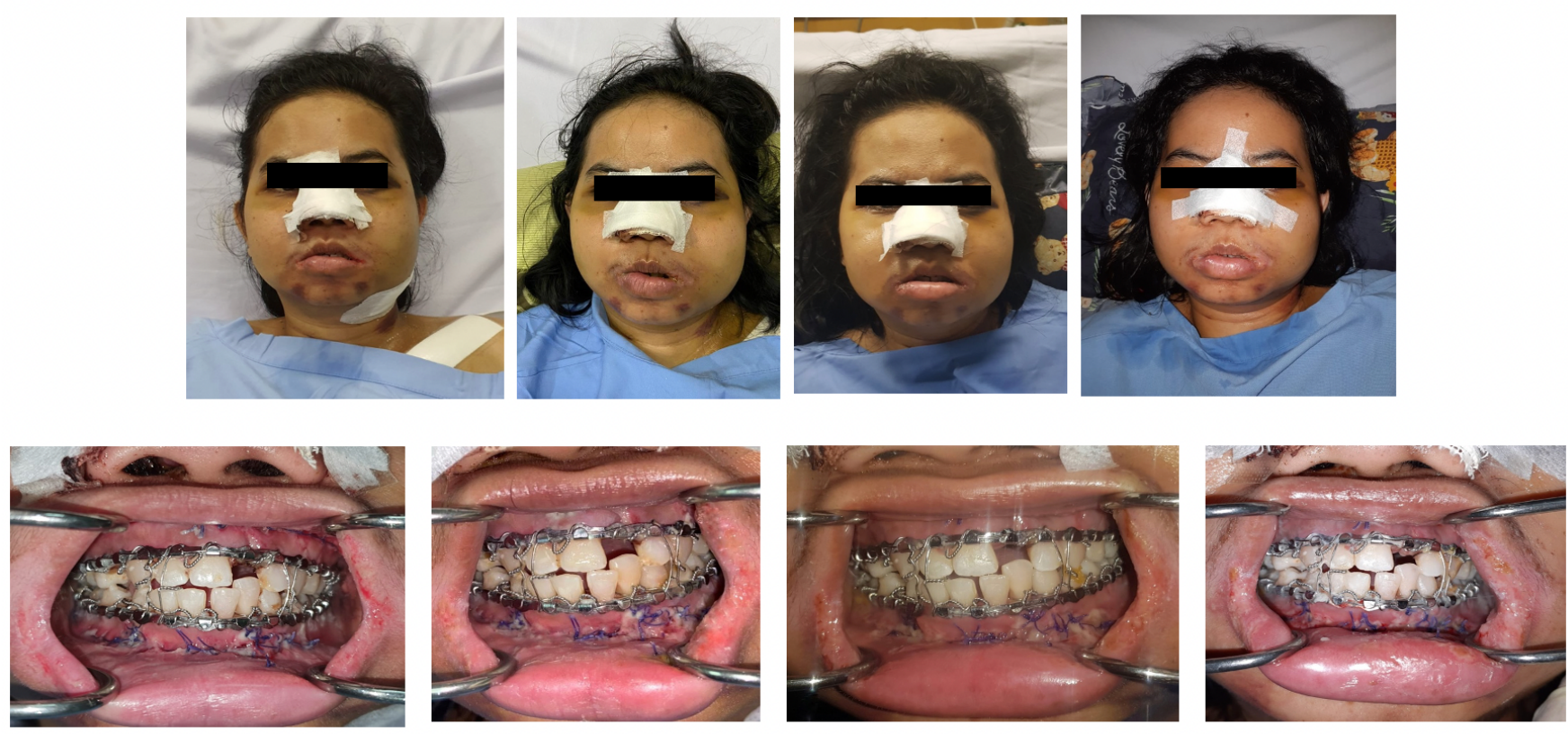

Figure 8. Post Operative Day 5-8

The wire was left in place for two weeks. Patients were asked to check every week. The intermaxillary fixation (IMF) wire was removed on the second week. The patient had no complaints, the right and left faces look symmetrical, and the feeling of thickness in the cheeks is reduced (Fig. 9). 

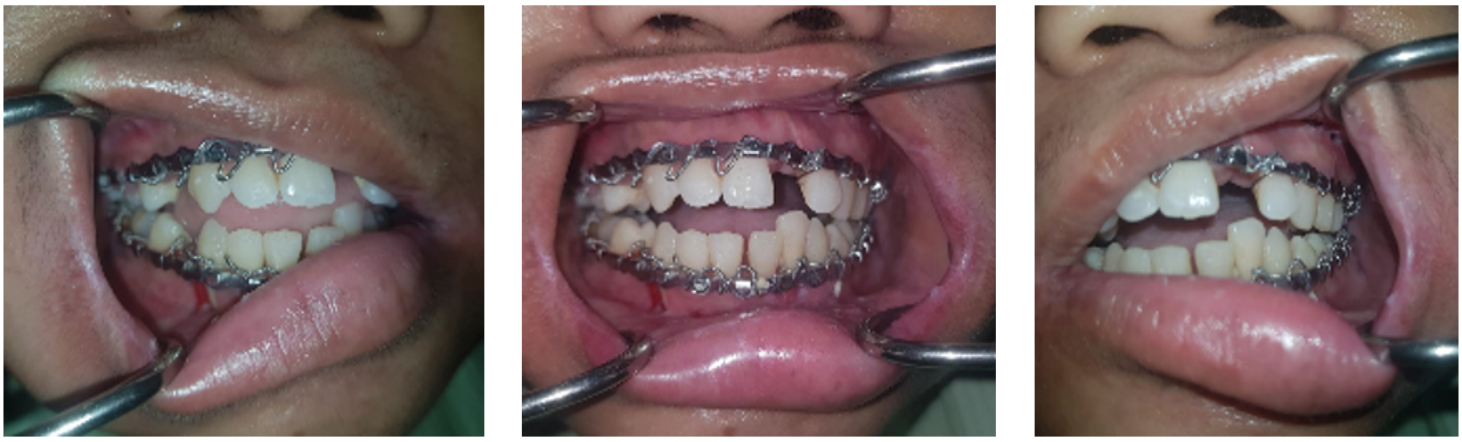

\section{Figure 9. Post Operative Day 2 weeks}

At the 4th week of control, the mandibular and maxillary erich bar were removed, the patient was examined for contact occlusion of the maxillary and mandibular teeth. After that, the patient had no more complaints about tooth contact and the treatment was declared complete (Fig. 10).
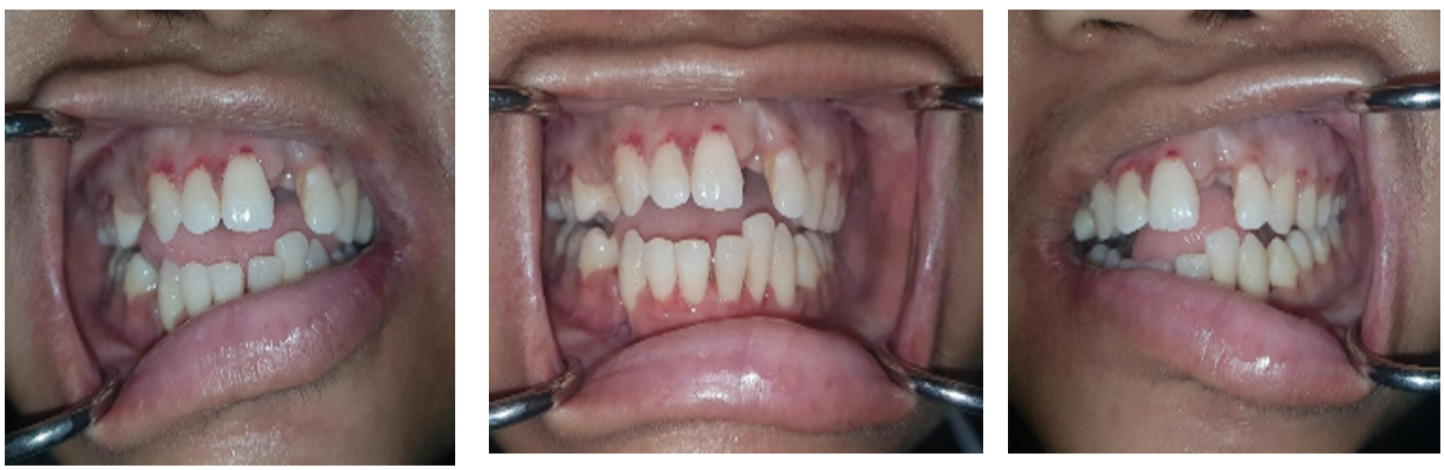

Figure 10. Post Operative Day 1 month

In the 3rd month, a panoramic radiograph examination was performed, the plate orientation was good. Contiguous and compressed fracture areas will heal by contact healing or direct bone formation without callus formation (Fig. 11).

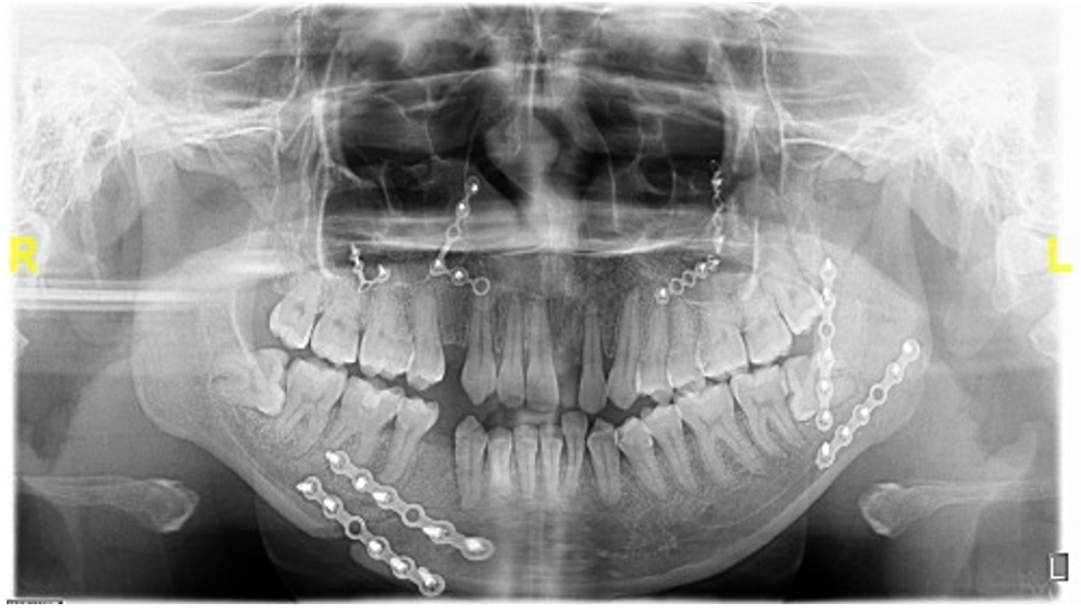

Figure 11. Post Operative Day 3 months 


\section{DISCUSSION}

Maxillofacial fractures cannot be separated from head injuries because of their adjacent location and structures. Patients with maxillofacial fractures are often accompanied by head injuries, such as intracranial hemorrhage, skull base fractures and decreased consciousness which can result in damage to the central nervous system. Direct trauma usually occurs in the occipital, mastoid, supraorbital area, while indirect trauma usually occurs on the face, where then the force is transmitted through the bones of the face or lower jaw. 3,6,9

Based on history taking, physical examination, and investigations, this case was diagnosed with a mild head injury. Head injury is one of the main causes of death and disability in the productive age group and mostly occurs due to traffic accidents. The initial management of patients with head injuries basically has the aim to monitor as early as possible and to prevent secondary head injuries, as well as to improve the general condition as optimally as possible so that it can help in healing diseased brain cells. ${ }^{11,13,15}$

The os zygoma is a prominent bone in the face and will get the strongest impact force on a traumatized face. The zygomatic bone is closely related to the maxillary, forehead and temporal bones, and because these bones are usually involved when the zygomatic bone is fractured, it is more accurately called a zygomatic complex fracture. ZMC fractures can be characterized by swelling accompanied by periorbital hematoma and subconjunctival hemorrhage, asymmetrical facial contours, crepitus, nasal bleeding on the fractured side. The zygomaticomaxillary complex (ZMC) has an important role in the structure, function, and aesthetic appearance of the face. The ZMC provides a normal cheek contour and separates the orbital contents from the temporal fossa and maxillary sinus. The zygoma is the attachment site of the masseter muscle, therefore its damage will affect the chewing process. In this patient, bone discontinuities occurred in the four supporting walls of the left zygoma: the zygomaticomaxillary, frontozygomatic, zygomaticosphenoid, and left zygomaticotemporal. ${ }^{8,12,13}$

Emergency measures performed by the Neurosurgery section were close observation of the patient's consciousness with GCS assessment, and vital signs, the head position of the patient "head up 30" aims to reduce intracranial pressure in head injury patients, besides, this position can also increase oxygen to the brain. The ABCDE assessment is a priority examination based on the type of wound, vital signs and mechanism of injury, so that lifethreatening conditions are quickly recognized. ${ }^{17,19,20}$

In the neurological examination of nerve I-XII, there were no abnormalities, physiological reflexes were neither increased nor decreased, pathological reflexes were absent, stimulation of the lining of the brain was also not found to be abnormal. In this case, the supporting examination that has been performed was a CT scan of the head, the result is no calvarial fracture or extra and intraaxial bleeding. ${ }^{4,10,14}$

In fractures of the middle third of the face that can alter the occlusal relationship, such as Lefort I, II, and III fractures, the investigation for a suitable occlusal relationship is a top priority before reducing repositioning of the fracture fragments. To restore the occlusion to a suitable (normal) occlusion, that is, by placing the maxilla in a proper occlusion relationship with the mandible. After the occlusion was obtained, an elastic rubber was attached to maintain the occlusion relationship. Care should be taken not to lock with wires to maintain occlusion, if there is an injury to the skull base. Then, proceeding with repositioning and fixation of fracture fragments and installation of plates. $1,7,17$

Management of patients with facial trauma must be comprehensive and at the same time seeking all the locations and extent of all injuries. The goal of treatment for patients with craniomaxillofacial injuries should be synergized with all injuries. Both soft tissue injuries and fractures should be assessed, and a treatment plan should be established. Treatment goals should include restoration of function and appearance. Surgical treatment of facial fractures involves adequate exposure, thorough reduction, and stable fixation of the fracture. ${ }^{7,11,20}$

Management of mandibular fracture cases requires a comprehensive understanding of anatomical, biomechanical, and occlusion factors. These three factors aim to restore mandibular function which is highly dependent on the anatomical position of the bone fragments, with minimal morbidity. Plates and screws have been used over the past few decades to facilitate stability of bone fragments in the maxillofacial region, and are currently the most frequently used technique. $6,7,9$

The open reduction technique with internal fixation or known as open reduction and internal fixation (ORIF) in facial trauma was introduced in 1975. This technique applies the principle of orthopedic materials to the facial bones using plates and screws. This technique is considered simple by creating a stability of fractured bone fragments by compression method. Restoring these anatomical positions and supporting structures is key to fracture reduction. Anatomical reduction of thin bone should also be obtained, especially the bone that forms one of the walls of the orbit. Anatomical reduction can serve as a frame of reference that guides the replacement of misaligned bone fragments into parallel positions. In multiple facial trauma, anatomic reference points may be more difficult to expose and may be comminuted and therefore unable to provide proper reduction, so open reduction and internal fixation in this patients was initiated from the mandible to restore the anatomical position and supporting structures which are the key to fracture reduction. ${ }^{1,6,17}$ 
The open reduction internal fixation (ORIF) procedure in this case was performed one week after the trauma, there were problems with the left maxillary comminuted fragment. Reduction of zygmoatic complex fractures becomes more difficult with time, and surgery may be delayed up to 10 days if necessary to wait for the edema to subside, making it easier to manipulate the fracture area and soft tissue. Performing treatment more than this time will complicate the procedure because fibrosis has occurred, and early healing has been established. On the 14th day of control, the thick sensation in the cheek began to decrease, which indicated that there had been decompression of the left infraorbital nerve. ${ }^{15,18,20}$

Stabilization of complex fractures requires more points of fixation so that if it is not strong enough it increases the risk of healing complications such as malunion or nonunion which results in poor occlusion. After reduction and fixation of the mandibular fracture, the fractured segment must also resist the pull of the masticatory muscles. A slight change in the occlusion of the mandible will generate proprioceptive nerve impulses in the temporomandibular joint capsule which will provide feedback signals that force the contralateral muscles of mastication to compensate. $7,9,13$

\section{CONCLUSION}

Multiple facial fractures require comprehensive management involving multiple disciplines. Patients with a history of head injury are closely related to trauma that occurs in the facial area. A comprehensive initial assessment is very essential in determining the treatment plan in maxillofacial trauma patients. Facial fractures can result in a deformity and loss of facial function that affects the social life of the patient. The ORIF procedure performed in this case was able to restore the facial deformity and restore masticatory function with a good prognosis.

\section{REFERENCES}

1. Adiantoro S, Kasim A, Faturrahman F. Management of Le Fort II fracture accompanied with blowout fracture of orbital base: a case report. J Dentomaxillofacial Sci. 2017;2(2):143-6.

2. Bradley D, Leung B, Saxena S, Dungarwalla M, Chapireau D, Fan K. Surgical management of zygomatic complex fractures in a major trauma centre. Plastic and Aesthetic Research. 2019;6.

3. Esmaeelinejad M. Maxillofacial fractures: from diagnosis to treatment. Trauma Surgery: IntechOpen; 2018.

4. Iskandar MK, BS S, editors. Diagnosis Dan Penanganan Cedera Kepala Di Daerah Rural. Aceh Surgery Update 2; 2017.

5. Joshi UM, Ramdurg S, Saikar S, Patil S, Shah K. Brain injuries and facial fractures: A prospective study of incidence of head injury associated with maxillofacial trauma. Journal of maxillofacial and oral surgery. 2018;17(4):531-7.

6. Luciana L, Oggy BAR, Wiargitha IK, Irawan H. Management of Maxillofacial Fracture: Experience of Emergency and Trauma Acute Care Surgery Department of Sanglah General Hospital Denpasar Bali. Open access Macedonian journal of medical sciences. 2019;7(19):3245.

7. Marantson N. Penggunaan Arch Bar pada Fraktur Dentoalveolar. Majalah Biomorfologi. 2019;29(1):19-26.

8. Nastri AL, Gurney B. Current concepts in midface fracture management. Current opinion in otolaryngology \& head and neck surgery. 2016;24(4):368-75.

9. Reksodiputro MH, Aldino N. Penatalaksanaan fraktur simfisis mandibula dengan dua perpendicular mini-plates. Oto Rhino Laryngologica Indonesiana. 2018;47(2):185-92.

10. Ruslin M, Wolff J, Yusuf HY, Arifin MZ, Boffano $P$, Forouzanfar T. The influence of helmet on the prevention of maxillofacial fractures sustained during motorcycle accidents. Cogent Engineering. 2018;5(1):1551170.

11. Tanuhendrata A, Hatibie M, Oley MC, Prasetyo E. Hubungan antara fraktur maksilofasial dengan terjadinya lesi intrakranial. JURNAL BIOMEDIK: JBM. 2016;8(3).

12. Vujcich N, Gebauer D. Current and evolving trends in the management of facial fractures. Australian dental journal. 2018;63:S35-S47.

13. Fonseca RJ. Oral and Maxillofacial Surgery: 3Volume Set: Elsevier Health Sciences; 2017.

14. Planas JH, Waseem M, Sigmon DFJS. Trauma primary survey. 2020.

15. Jose A, Nagori SA, Agarwal B, Bhutia O, Roychoudhury AJJoE, Trauma, Shock. Management of maxillofacial trauma in emergency: An update of challenges and controversies. 2016;9(2):73.

16. Joshi UM, Ramdurg S, Saikar S, Patil S, Shah KJJom, surgery o. Brain injuries and facial fractures: A prospective study of incidence of head injury associated with maxillofacial trauma. 2018;17(4):531-7.

17. Sastrawan AD, Sjamsudin E, Faried AJMKGI. Penatalaksanaan emergensi pada trauma oromaksilofasial disertai fraktur basis kranii anterior. 2017;3(2):111-7.

18. Martindale A. The Complete Drug Reference. London. The Pharmaceutical Press; 2017.

19. Azimi Far A, Abdoli A, Poorolajal J, Salimi RJHKJoEM. Paracetamol, ketorolac, and morphine in post-trauma headache in emergency 
department: A double blind randomized clinical trial. 2020:1024907920920747.

20. Braun TL, Maricevich RS, editors. Facial Trauma: Soft Tissue Management in Facial Trauma.
Seminars in plastic surgery; 2017: Thieme Medical Publishers. 